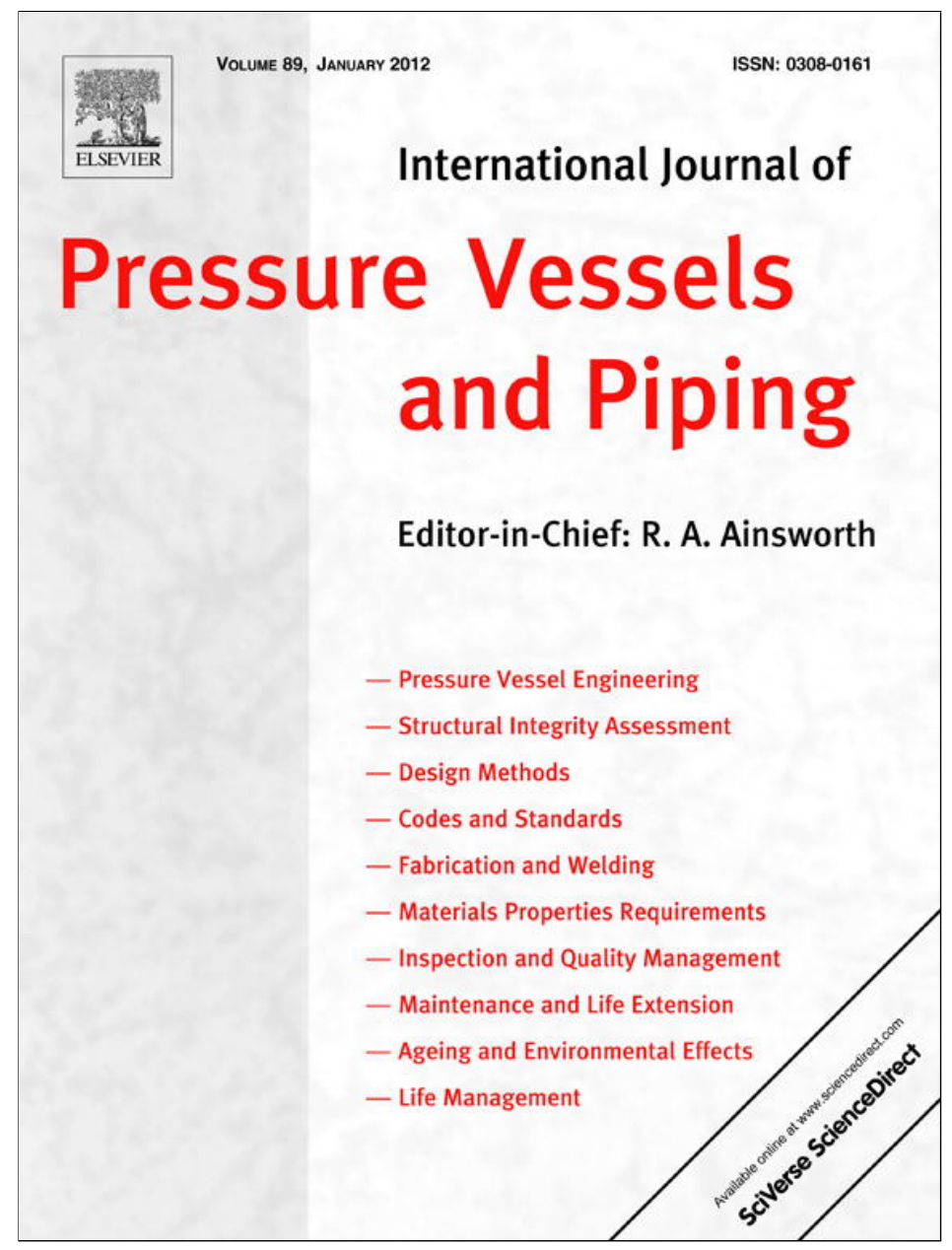

This article appeared in a journal published by Elsevier. The attached copy is furnished to the author for internal non-commercial research and education use, including for instruction at the authors institution and sharing with colleagues.

Other uses, including reproduction and distribution, or selling or licensing copies, or posting to personal, institutional or third party websites are prohibited.

In most cases authors are permitted to post their version of the article (e.g. in Word or Tex form) to their personal website or institutional repository. Authors requiring further information regarding Elsevier's archiving and manuscript policies are encouraged to visit:

http://www.elsevier.com/copyright 


\title{
Effects of stop-start features on residual stresses in a multipass austenitic stainless steel weld
}

\author{
M. Turski ${ }^{\mathrm{a}, *}$, J.A. Francis ${ }^{\mathrm{a}, \mathrm{b}}$, P.R. Hurrell ${ }^{\mathrm{c}}$, S.K. Bate ${ }^{\mathrm{d}}$, S. Hiller ${ }^{\mathrm{b}}$, P.J. Withers ${ }^{\mathrm{a}}$ \\ ${ }^{a}$ School of Materials, University of Manchester, Grosvenor Street, Manchester M1 7HS, United Kingdom \\ ${ }^{\mathrm{b}}$ Materials Engineering, The Open University, Walton Hall, Milton Keynes MK7 6AA, United Kingdom \\ ${ }^{\mathrm{c}}$ Rolls-Royce Plc., Raynesway, Derby DE21 7XX, United Kingdom \\ ${ }^{\mathrm{d}}$ Serco Technical Services, Birchwood Park, Warrington, Cheshire WA3 6GA, United Kingdom
}

\section{A R T I C L E I N F O}

\section{Article history:}

Received 24 March 2011

Received in revised form

19 August 2011

Accepted 25 August 2011

\section{Keywords:}

Arc instability

Multipass weld

Neutron diffraction

Residual stress

Stainless steel

Weld interruption

\begin{abstract}
A B S T R A C T
In this article we describe experiments that characterise and quantify the localised perturbations in residual stress associated with both ramped and abrupt stop-start features in a multipass weld. Residual stress distributions in AISI Grade 304L/308L stainless steel groove-welded specimens, containing weld interruptions that were introduced in a controlled manner, have been characterised using both neutron diffraction and the incremental deep hole drilling method. The extent to which the localised stresses associated with the interruptions were annealed by overlayed passes was also assessed. The results suggest that, regardless of the type of interruption, there can be significant localised increases in residual stress if the stop-start feature is left exposed. If further weld passes are deposited, then the localised increases in stress are likely to persist if the interruption was abrupt, whereas for a ramped interruption they may be dissipated.
\end{abstract}

(C) 2011 Elsevier Ltd. All rights reserved.

\section{Introduction}

Residual stresses can exacerbate many of the degradation mechanisms that are pertinent to power plant components, such as stress corrosion cracking [1], creep [2,3] and the development of fatigue cracks in and around weldments [4,5]. In addition to their role in accelerating the onset and accumulation of damage, residual stresses also affect the final fracture event [6,7]. In this context, it is hardly surprising that significant efforts have been directed at incorporating residual stresses into structural integrity assessment procedures for power plant infrastructure [8-10].

Welding operations introduce substantial residual stresses to power plant components due to the highly localised manner in which heat is applied. The temperature gradients associated with welding give rise to spatial and temporal variations in thermal expansion and contraction which leads to non-uniform plastic flow and associated misfit strains that generate residual stresses. While these stresses are introduced over a range of length scales [11], structural integrity assessments generally require only

\footnotetext{
* Corresponding author. Tel.: +44 (0)161 9111145.

E-mail address: Mark.Turski@magnesium-elektron.com (M. Turski).
}

knowledge of the macro (type I) residual stresses acting throughout the bulk of the component and in the vicinity of welds [12-14]. However, due to the practical difficulties that arise in measuring bulk residual stresses within thick components, it is usually necessary to obtain these stresses by combining carefully targeted measurements with predictions from numerical models.

One of the features of multipass welds that appears to have been given little or no attention, either from a measurement or modelling perspective, is that of a weld interruption. Practical requirements, such as the changing of a reel of filler wire or the grinding out of a weld defect, will often necessitate that the welding arc is temporarily extinguished. While the addition of filler material will continue once the arc is re-established, in the vicinity of the stop-start feature, the transient nature of the temperature field will lead to localised differences in microstructure and strain history, and hence corresponding perturbations in the residual stress field. On a practical level welding engineers often attempt to minimise these localised effects by specifying that, when weld interruptions take place, the welding current is ramped down prior to extinction of the arc and, similarly, is ramped up gradually upon re-ignition. Nevertheless, at present there is little knowledge of the extent to which localised stresses are introduced by abrupt weld interruptions, 
and there is a corresponding lack of information relating to the effectiveness of ramping down/up in minimising the impact of weld interruptions on residual stress distributions. There is some evidence, however, to suggest that transient temperature fields [15] and weld interruptions [16-18] may lead to changes in local residual stress levels.

In this article we quantify the extent to which a weld interruption introduces localised residual stresses into a multipass weld, and the extent to which these stresses may be annealed by subsequent weld passes. Three groove-welded specimens in $20 \mathrm{~mm}$ thick AISI grade 304L austenitic stainless steel plates were studied. Two of the specimens contained both an abrupt and a ramped weld interruption. In one of these specimens the interrupted weld run was left exposed while in the other subsequent weld passes were overlayed. A third specimen was also manufactured with no interruptions so that reference stress levels were available. The resulting residual stress fields were measured by neutron diffraction on the pulse overlap diffraction instrument (POLDI) at the Paul Scherrer Institute in Switzerland, and on the Stress-Spec diffractometer at FRM-II, Germany. After the neutron diffraction measurements were completed, further residual stress measurements were carried out using the incremental deep hole drilling method [19]. Finally, the features of the measured residual stress distributions were compared with the results of hardness mapping. In this article, the results from all experiments are discussed. It is hoped that the work presented here will contribute towards an understanding of the significance of weld interruptions, as well as ongoing improvements to welding procedure specifications and, more generally, power plant integrity.

\section{Welding trials}

Three blank plates measuring $200 \times 150 \times 20 \mathrm{~mm}^{3}$ were machined from AISI grade $304 \mathrm{~L}$ stainless steel. A $10 \mathrm{~mm}$ deep groove was then machined down the centre of each plate (Fig. 1). After machining, each specimen was solution annealed in a vacuum furnace at $1050^{\circ} \mathrm{C}$, and then gas fan quenched to achieve a compromise between the avoidance of stress generation on cooling while simultaneously guarding against sensitisation. In each plate, weld beads were then deposited within the machined groove. Welding was carried out with the gas-tungsten arc welding (GTAW) process using an AISI grade 308L filler wire, $0.9 \mathrm{~mm}$ in diameter, with argon as the shielding gas. The tungsten electrode was the cathode and a pulsed current was used, with the peak current ranging from 180 to $200 \mathrm{~A}$ and the background current ranging between 130 and $150 \mathrm{~A}$. The pulsing frequency was $1 \mathrm{~Hz}$ with the peak current being applied for $50 \%$ of the duration of each cycle. The welding speed was $75 \mathrm{~mm} /$ min, resulting in a nominal heat input of approximately $1.3 \mathrm{~kJ} / \mathrm{min}$. The plates were unrestrained during welding and the interpass temperature did not exceed $70{ }^{\circ} \mathrm{C}$ for any of the weld passes.

Details of the first specimen (Plate 1 ) have been reported previously [20], but they will also be summarised here as they provide a foundation for the current work. This specimen contained five weld passes, which were each deposited in the form of stringer weld beads: that is to say that no weaving took place. The first pass was placed along the groove centreline, with subsequent passes being laid down alternately on either side of the centreline (Fig. 1). Importantly, the fifth and final stringer weld pass in Plate 1 was interrupted at two locations. The first interruption comprised a ramping down in welding current over $10 \mathrm{~mm}$ of travel starting at

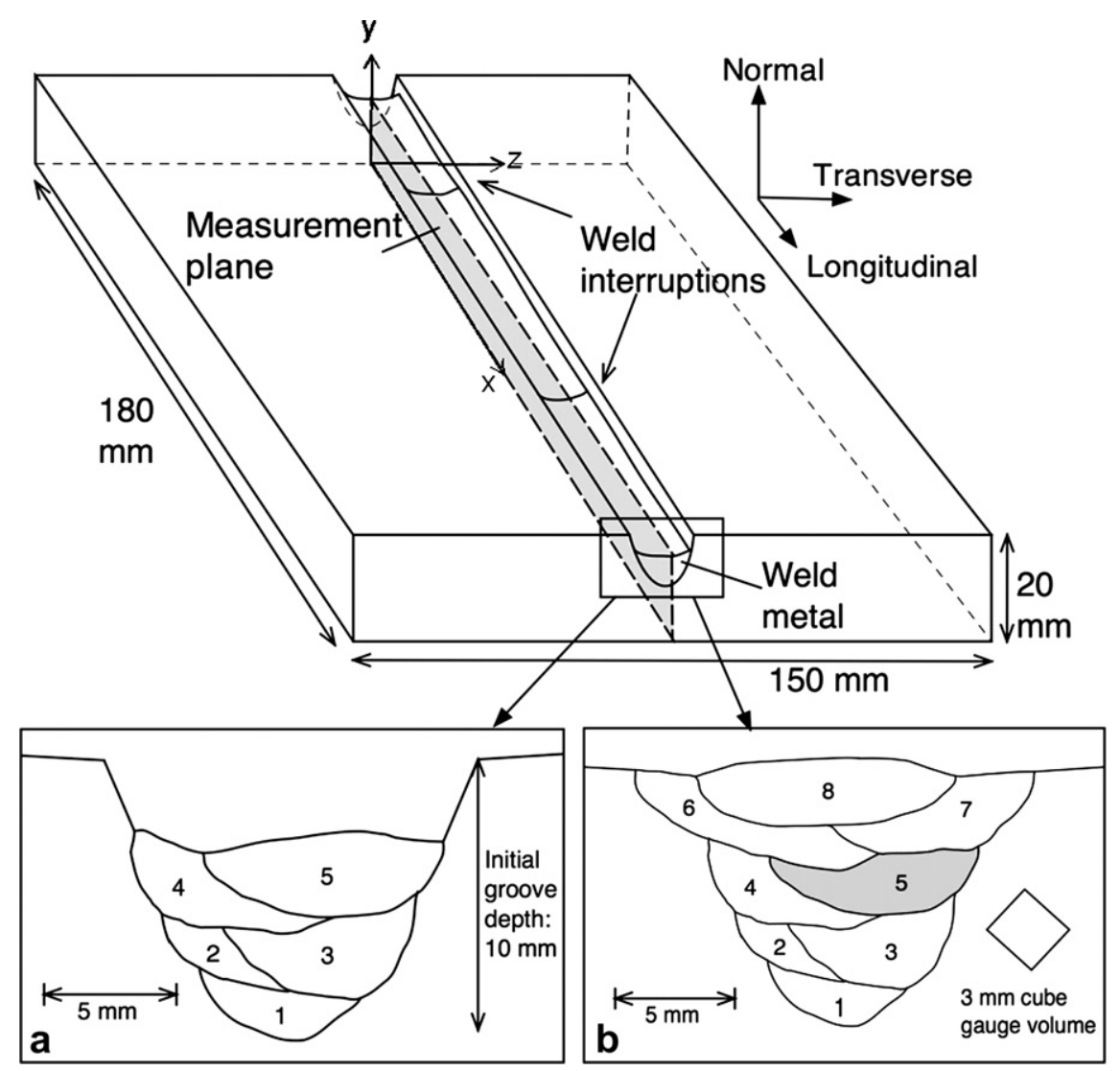

Fig. 1. Geometry of groove-welded plate along with the locations of individual weld beads as determined from a companion GTAW test weld for (a) Plate 1 and (b) Plates 2 and 3. The weld beads have been numbered according to the deposition sequence. 
$65 \mathrm{~mm}$ from the beginning of the plate (Fig. 1). The pass was then restarted $55 \mathrm{~mm}$ from the beginning of the plate, with a corresponding ramping up of the welding current, thus providing $20 \mathrm{~mm}$ of overlap between the end of the stop and the beginning of the restart. The second interruption occurred abruptly at $135 \mathrm{~mm}$ from the beginning of the plate (Fig. 1). In this case the pass was restarted at the same location as the abrupt stop, so that nominally there was no overlap. Thus Plate 1 was intended to provide two different types of interruption that would be left exposed in a way that would be analogous to having interruptions in the final capping pass of a welded joint.

A photograph of Plate 1 is included in Fig. 2 with higher magnification images of interruptions, as obtained on similar test plates welded using the same nominal parameters, included as insets. An examination of the weld craters suggested that the weld pool was approximately $10 \mathrm{~mm}$ in length, with minimal eccentricity. Run-on and run-off tabs were not used but, in all cases, the distance between the interruptions or between the interruptions and the nearest end of the plate was approximately six times larger than the length of the weld pool. It was hoped that these distance were sufficiently large to minimise the influence of transience on the residual stresses measured at the interruptions.

For Plate 2, the first five weld passes were deposited in exactly the same manner as for Plate 1, including the interruptions in the fifth pass. However, a further three stringer weld beads were then overlayed on to the first five passes, resulting in a total of eight passes and complete filling of the weld groove (Fig. 1). The intention here was to accommodate the possibility that subsequent thermal cycles might lead to full or partial annealing of any localised residual stresses that may be associated with the stop-start features. Finally in the third plate, eight stringer weld passes were deposited and there were no interruptions in any of the weld passes. The configuration of the weld passes is also as shown in Fig. 1.

\section{Neutron diffraction}

Neutron diffraction measurements were carried out on Plates 1 and 3 [20] at the POLDI instrument (Pulse OverLap DIffractometer) in Switzerland. POLDI is a type of time-of-flight (TOF) diffractometer, allowing a complete diffraction pattern to be acquired at a fixed diffraction angle, $2 \theta$. In this work all measurements at POLDI were carried out using a scattering angle $2 \theta=90^{\circ}$, with a $5 \times 2.5 \times 3.8 \mathrm{~mm}^{3}$ nominal gauge volume, and all measured elastic strains were based on the $\{311\}$ crystal reflection.

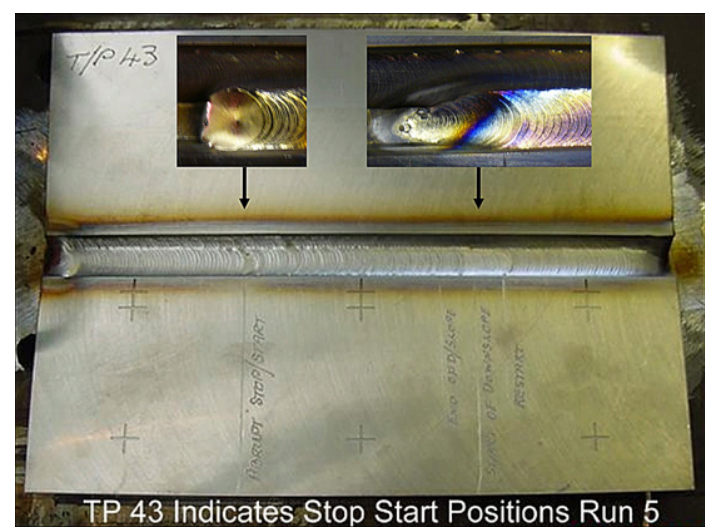

Fig. 2. Photograph of Plate 1 with fifth weld pass offset to one side of the groove (i.e. offset towards bottom of image). The welding direction was from right to left. Higher magnification images of ramped (right) and abrupt (left) interruptions are included as insets. The inset images were obtained from another test plate which was welded using the same nominal conditions. The weld pool was approximately $10 \mathrm{~mm}$ in length.
Many TOF diffractometers use pulsed spallation, which enables the velocity and hence wavelength of any diffracted neutron to be determined by recording the time that elapses between the spallation pulse and the arrival of the neutron at the detector. However, most TOF diffractometers generally require the time between pulses to be long enough so that the fastest neutrons from one pulse cannot catch up with the slowest ones from the preceding pulse (i.e. they require avoidance of frame overlap). Unfortunately, this 'waiting time' between pulses limits the effective neutron flux and hence increases the measurement time required at the instrument. In contrast, POLDI overlaps individual pulses, allowing an increase in effective flux while retaining the intrinsic advantages of a TOF instrument. The overlapping TOF diffraction patterns are deconvolved by recording both the time of flight and the scattering angle of the diffracted neutrons. Neutron counts are collected by a timefocused ${ }^{3} \mathrm{He}$ position-sensitive detector over a $30^{\circ}$ range in scattering angle.

Plate 2 was measured using the STRESS-SPEC diffractometer at the FRM-II reactor source in Munich, Germany. Measurements were made using a nominal $3 \times 3 \times 3 \mathrm{~mm}^{3}$ gauge volume, with the wavelength of the neutrons being approximately $1.672 \AA$, and in all cases the measured elastic strains were based on the $\{311\}$ crystal reflection. This combination of wavelength and crystal reflection resulted in diffraction angles that were approximately $90^{\circ}$, resulting in nominal measurement gauge volumes that closely resembled a cube.

For all samples, measurements of residual elastic strain were made along 3 orthogonal directions (Fig. 1) that were parallel to the axes of the plates. The longitudinal orientation may also be assumed to correspond to the maximum principal stress direction. However, the orientation of the principal stresses in the transverse-normal plane may rotate within that plane, particularly within the vicinity of weld beads. Nevertheless, the authors believe that the axes of the plate make for a convenient coordinate system and presentation of results.

At each measurement location, elastic strains were obtained by comparing the lattice spacing that is measured in the location of interest, $d_{311}$, with the lattice spacing that is measured in an equivalent volume of material that is free of macroscopic stress (this stress-free lattice spacing is referred to as $d_{0}$ ), according to the following equation:

$\varepsilon_{311}=\frac{d_{311}-d_{0}}{d_{0}}$

here $\varepsilon$ denotes elastic strain and the subscript " 311 " denotes the lattice reflection that was used to provide the estimate for strain. Once the elastic strains in the three orthogonal directions are available, estimates for the stress acting in each direction can then be obtained at each measurement location using a generalised form of Hooke's law [21]

$\sigma_{x x}=\frac{E_{311}}{\left(1+v_{311}\right)} \varepsilon_{x x}+\frac{v_{311} E_{311}}{\left(1+v_{311}\right)\left(1-2 v_{311}\right)}\left(\varepsilon_{x x}+\varepsilon_{y y}+\varepsilon_{z z}\right)$

here $\sigma_{x x}$ corresponds to a stress acting in the $x$ direction on a plane which itself has its normal aligned in the $x$ direction, $y$ and $z$ denote the two remaining mutually-orthogonal coordinate axes, $v_{311}$ is the plane-specific Poisson's ratio, and $E_{h k l}$ is the plane-specific elastic modulus for the material.

Throughout this study, the $\{311\}$ lattice reflection was chosen as the basis for measuring residual elastic strains because the stress-strain response of this plane has been shown to be the most representative for austenitic stainless steel bulk properties [22]. 
Furthermore, plane-specific values for Young's modulus (183.5 GPa) and Poisson's ratio (0.31) were used in equation (2) to convert residual elastic strain measurements in to estimated stresses. These values were taken from [23] and are based on the Kröner model [24]. Clearly, the estimates for residual stress are dependent on the values that are used for the plane-specific modulus and Poisson's ratio, and it is possible that the values we have used are not truly representative of AISI grade 308L weld metal, particularly if a strong weld metal texture were to exist. While it is known that strong weld metal textures can arise in AISI grade 316L weld metals [25], measurements made on weld metal taken from Plate 3 showed that there was not any significant texture [26].

In this study, all of the measurement locations resided along the plane of the weld centreline, which passes through the middle of the weld groove and runs parallel to the welding direction (Fig. 1). Within this measurement plane, the origin of the coordinate system for the measurement positions was defined by the intersection of the end of the plate at which the weld was started $(x=0)$ and the bottom surface of the plate $(y=0)$.

It is acknowledged that, in general, significant residual stresses can also exist at locations other than those on the plane of the weld centreline such as, for example, in the heat-affected zone (HAZ). Previous work by Suzuki and Holden [27] found that, for a butt weld in AISI grade 304L stainless steel using an AISI grade 308L filler metal and the GTAW process, the highest tensile residual stresses, at approximately $360 \mathrm{MPa}$, were found to exist in the longitudinal orientation at a location that was offset from the weld centreline by $6 \mathrm{~mm}$. On the weld centreline itself the residual stresses were found to be approximately $300 \mathrm{MPa}$ in tension. The uncertainties associated with their measurements were in the order of $\pm 30 \mathrm{MPa}$. While the residual stresses on the weld centreline were not found to be the maximum stresses in this case, they were clearly still close to the maximum stresses, and the possibility of introducing localised increases in stress to the weld metal, associated with weld interruptions, might still provide cause for significant concern. Furthermore, it should also be noted that, in general, the exact location of the maximum residual stresses will be a function of the relative strengths of the weld metal and parent metal, and the extent to which each of these undergoes cyclic hardening during welding.

In this study, the objective was not to undertake a general characterisation of the residual stress distributions that are generated in welds under steady-state conditions, but rather to establish the extent to which weld interruptions may lead to localised increases in residual stress. That is to say, we were primarily interested in quantifying any increases in stress that occurred at interruptions, relative to the stresses that would otherwise have existed, had steady welding conditions been maintained at all times. In this respect, the authors believed that, by focussing on the residual stresses residing in the plane of the weld centreline, they would capture the nature of any transient features that might arise with the distance along a weld bead containing an interruption, and that such an approach would also make efficient use of the neutron beam time that was available.

Fig. 3a, b, and c shows the respective positions of the neutron diffraction measurements within Plates 1, 2 and 3. In Plates 1 and 2 , measurements were made along a line within the weld metal corresponding approximately to the position of the fifth weld pass $(y=13 \mathrm{~mm})$, in order to identify variations in residual stress along the length of the weld that may be attributed to the different stop-start effects. In all three plates, measurements were also made down through-thickness lines at $x=65,110$, and $135 \mathrm{~mm}$. The $x=65$ and $135 \mathrm{~mm}$ positions correspond to the ramped weld interruption and the abrupt weld interruption respectively, while it is expected that at $x=110 \mathrm{~mm}$ the welding conditions would have approached a steady state between the two weld interruptions. The through-thickness line at the middle of the plate $(x=100 \mathrm{~mm})$ was not selected due to the presence of a drilled thermocouple hole at that location. Additional measurement positions were also interrogated in Plates 1 and 2, as is shown in Fig. 3a and b, to allow a map of residual stress to be generated over the measurement plane.

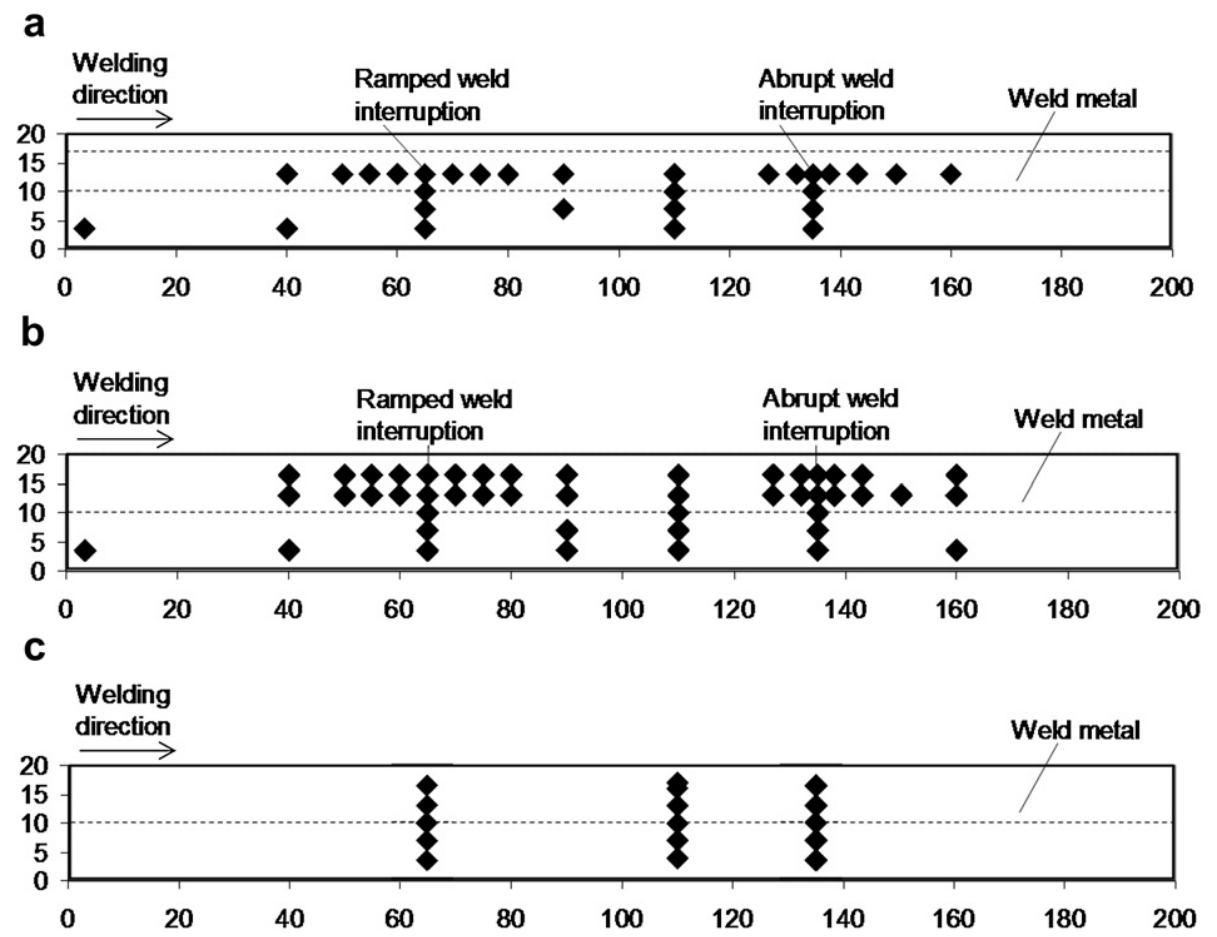

Fig. 3. Measurement positions within AISI grade 304L/308L austenitic groove welds for (a) Plate 1 (b) Plate 2 and (c) Plate 3. 


\section{Determination of stress-free lattice parameter $\left(d_{0}\right)$}

Since welds introduce gradients in both microstructure and strain history to a component, it is recommended that positiondependent values for $d_{0}$ are determined [28]. In this work a companion 8-pass groove-welded plate was manufactured to the same geometry and from the same batch of material, to provide for $d_{0}$ specimens. Cuboids measuring $4 \times 4 \times 5 \mathrm{~mm}^{3}$ were then cut from the plane of the weld centreline in this plate using wire electro-discharge machining (EDM). The dimensions of the cuboids were judged to be sufficiently small for relaxation of the macro stresses that would have existed within the welded plate. The cuboids were cut in such a way that the $5 \mathrm{~mm}$ dimension was parallel to the normal direction of the plate.

The approach used for this investigation was to extract a number of cuboids from different locations along the length of the weld to allow an 'averaged' weld metal $d_{0}$ to be measured. As such, one set of $d_{0}$ cubes was extracted from weld metal that resided near the base of the groove, i.e. close to the mid-thickness of the plate, and another set was extracted from just under the top surface of the weld. This would have reduced the likelihood that any effects of weld metal dilution, or cyclic hardening associated with the welding thermal cycles, would adversely affect estimates for strain. In the same way, cuboids of the same dimensions were extracted from below the base of the groove to produce parent metal $d_{0}$ specimens. After extraction, each set of cuboids was subsequently joined together to produce a composite $8 \times 8 \times 5 \mathrm{~mm}^{3}$ cuboid. These composite cuboids were produced for convenience: to allow the same experimental arrangement to be used at each diffractometer for both $d$ and $d_{0}$ measurements. This eliminated the need for corrections between different experimental arrangements and provided for the most efficient use of allocated measurement time.

Finally, separate measurements of $d_{0}$ were made at each diffraction facility for weld and parent metal. A third $d_{0}$ value was also calculated for the heat-affected zone (HAZ) material to account for cases in which the gauge volume might contain both weld metal and parent metal (i.e. at $y=10 \mathrm{~mm}$, at the nominal root of the weld). This HAZ $d_{0}$ value was calculated by taking an average of the parent and weld metal $d_{0}$ value.

\section{Residual stress distributions}

Contour maps for the residual stress distributions in each sample were produced by generating an array of data points over a $2.5 \mathrm{~mm} \times 2.5 \mathrm{~mm}$ spacing, using a Matlab 'v4' gridding method [29]. This approach involved fitting the measured data in two dimensions using Green's functions of the biharmonic operator [30].

Fig. 4 shows the contour maps for the three components of residual stress in the measurement plane for Plate 1 . Recall that in this specimen the groove was only partially filled. A visual inspection of the sample revealed that the top surface of the weld metal corresponded approximately to $y=16.5 \mathrm{~mm}$. In Fig. 4 , however, the contour plots give estimated stresses only for locations between the back surface of the plate $(y=0)$ and positions near to the top of the weld metal $(y=15 \mathrm{~mm})$. The authors were mindful that the array of measurement points for this sample did not include any locations for which the centre of the gauge volume had a $y$-coordinate exceeding $13 \mathrm{~mm}$. Thus, in order to guard against the possibility of drawing conclusions based on extrapolated trends, the contour maps were limited to a maximum $y$-value of $15 \mathrm{~mm}$.

It can be seen that in the case of the longitudinal stress, there is a gradual transition from compressive stresses at the bottom surface of the plate $(y=0)$ to large tensile stresses towards the top of the weld metal region. This would seem reasonable since the last weld passes to be deposited were located towards the top of the groove, and one would expect there to be tensile residual stresses associated with these passes. While it is not a physical requirement for the longitudinal residual stresses to balance over the measurement plane it does appear that the longitudinal stress near the bottom surface is of opposite sign.

The transverse stress map in Fig. 4 displays some similar features to that for longitudinal stress. Tensile residual stresses are evident near to the top of the measurement plane, with a transition to compressive stresses towards the bottom of the plate. In this instance, there is a physical requirement for the stresses to balance over the measurement plane, although it should also be noted that the entire plane is not represented here. It is possible that the two highly compressive regions near to the bottom of the transverse stress map are in part artefacts arising from a poor extrapolation, noting that there is a sparsity of measurement points in those regions.

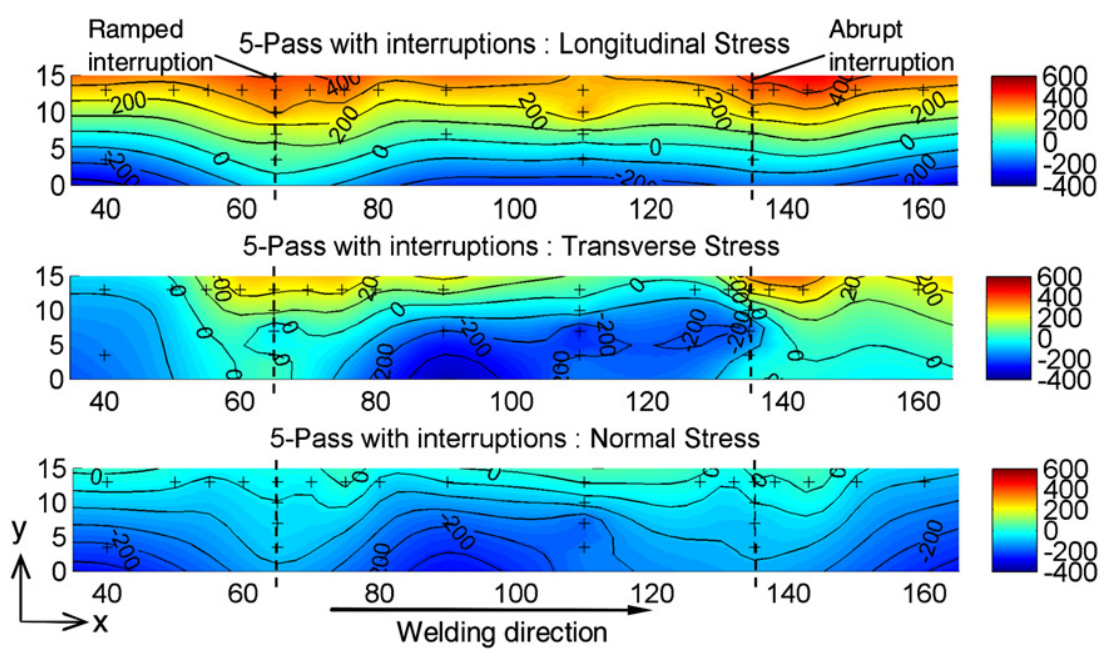

Fig. 4. Residual stress maps for the measurement plane in Plate 1. From top to bottom: longitudinal, transverse and normal residual stress (MPa). The nominal locations of the two weld interruptions have been highlighted. Note that the contour maps are only $15 \mathrm{~mm}$ in height, since the weld groove was only partially filled. Welding direction from left to right. 
Nevertheless, it would also appear that the stresses approximately balance over the portion of the measurement plane that is presented, suggesting that the measurements are self-consistent.

It is important to note that tensile stress 'hot spots', approaching $400 \mathrm{MPa}$ in magnitude, are present at the weld stop-start locations in both the longitudinal and transverse stress maps. Furthermore, it can be seen that the localised increases in stress appear to be more pronounced for the abrupt interruption than for the ramped interruption. The effects of the interruptions are perhaps more striking in the map of the transverse component of residual stress, which clearly reveals that the localised stresses are more concentrated in the case of the abrupt interruption. Here, peak tensile stresses in excess of $200 \mathrm{MPa}$ are seen at both interruptions, compared to values closer to zero in the middle of the plate where steady-state welding conditions would be expected.

Finally, the normal stresses in Fig. 4 are generally low when compared to the longitudinal and transverse stresses, as might be expected. There are two compressive lobes towards the bottom of the plate, but these may be artefacts associated with poor extrapolation in regions where there is a sparsity of measurement points. Clearly, the normal stress must be zero at the back surface of the plate. However, the authors chose not to enforce this boundary condition when constructing the normal stress maps, so this map does provide some indication of the stability of the contour mapping procedure. Over much of the back surface of the plate, the contour map suggests that the normal stress is relatively low (approximately $100 \mathrm{MPa}$ in compression) despite the fact that few measurements were made near this surface. It should also be noted that in the weld metal and, in particular, the regions surrounding the interruptions, the maps are likely to be substantially more informative and stable due to the higher density of measurement points. Nevertheless, given that in some regions within this specimen the measurement points were sparsely distributed, the authors have endeavoured, wherever possible, to draw conclusions relating to this specimen based on measured data, rather than the associated contour maps.

Fig. 5 shows the corresponding maps of residual stress for Plate 2. While there are features that are similar to the maps presented in Fig. 4, there are also differences, and some of these can be attributed to the increased number of measurement points. For example, it can be seen that the compressive lobes that were seen in the normal stress at the back surface of Plate 1 (Fig. 4) are not evident in Plate 2. Furthermore, the normal stresses at the back surface are determined to be close to zero, which suggests that the contour mapping procedure was more stable in the sparser regions towards the back surface of this specimen. Meanwhile, close to the top of the contour map, the normal stresses can be seen to be approximately $100 \mathrm{MPa}$ in tension. This is possible because a visual inspection of the completed weld revealed that the top of the weld metal on the measurement plane corresponded to approximately $y=21.5 \mathrm{~mm}$ : that is to say there was a small surplus of weld metal (reinforcement). Furthermore, as weld passes are deposited, there is a progressive increase in constraint upon cooling after welding, which may give rise to an increase in the hydrostatic (and hence normal) component of stress.

The transverse stress map, although slightly tensile overall, is reasonably close to satisfying stress balance. There are still compressive lobes towards the back surface of the plate, but the magnitudes of the mapped stresses have reduced when compared to the corresponding map in Fig. 4. It must also be remembered that the entire plane is not represented in Fig. 5, so that it is not possible to check the balancing of residual stresses with accuracy. Nevertheless, all three of the contour maps presented in Fig. 5 appear to be feasible and well behaved.

It is interesting to see that the map for longitudinal stresses in Plate 2 (Fig. 5) shows that the highest tensile residual stresses reside at a depth that corresponds approximately to the fifth weld pass. This general trend might arise due to the effects of cyclic hardening of the weld metal, which is known to play a significant role in determining residual stress distributions in austenitic stainless steel welds [31]. Although the final weld passes will have associated tensile contraction strains, the weld metal that was deposited in these passes will not have experienced the same extent of cyclic hardening as earlier weld passes. In contrast, weld metal that was deposited in passes 4 and 5, for example, will have been strain hardened by the thermal cycles associated with passes 6,7 and 8 , and the associated increase in yield stress leads to an increased ability to sustain residual stress. While the weld metal

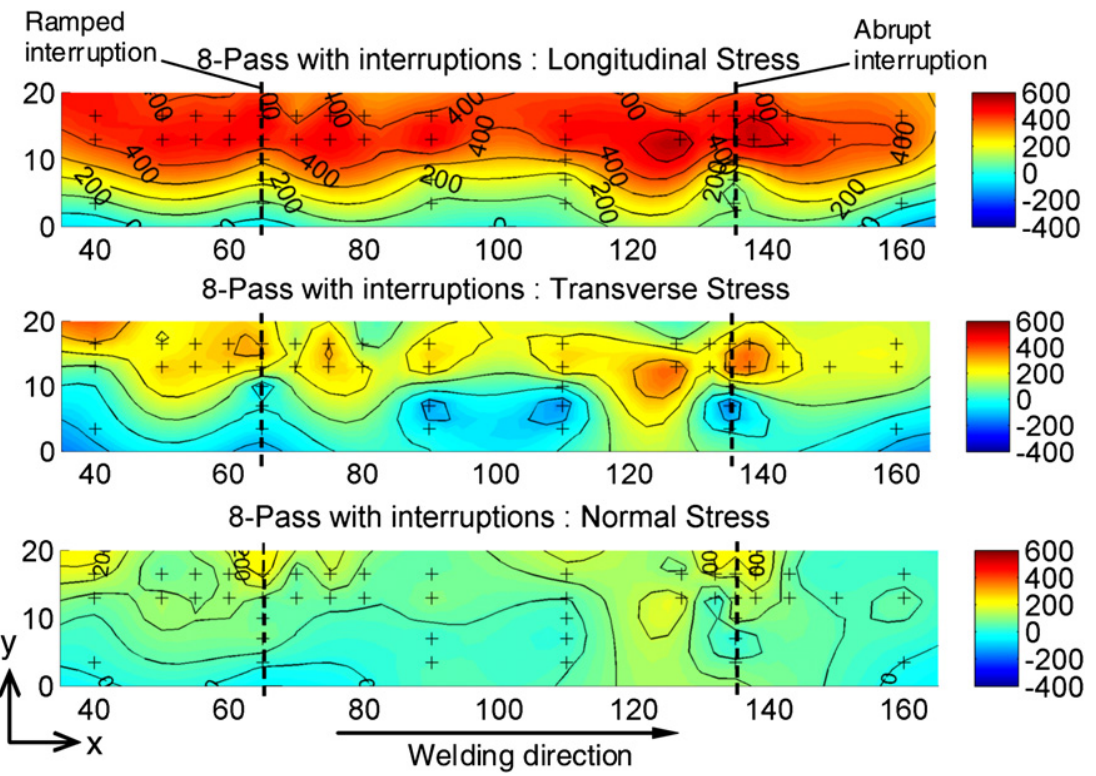

Fig. 5. Residual stress maps (in MPa) for Plate 2: an 8-pass groove weld specimen in AISI grade 304L/308L austenitic stainless steel containing weld interruptions in the 5th weld pass. The nominal locations of the two weld interruptions have also been highlighted. 


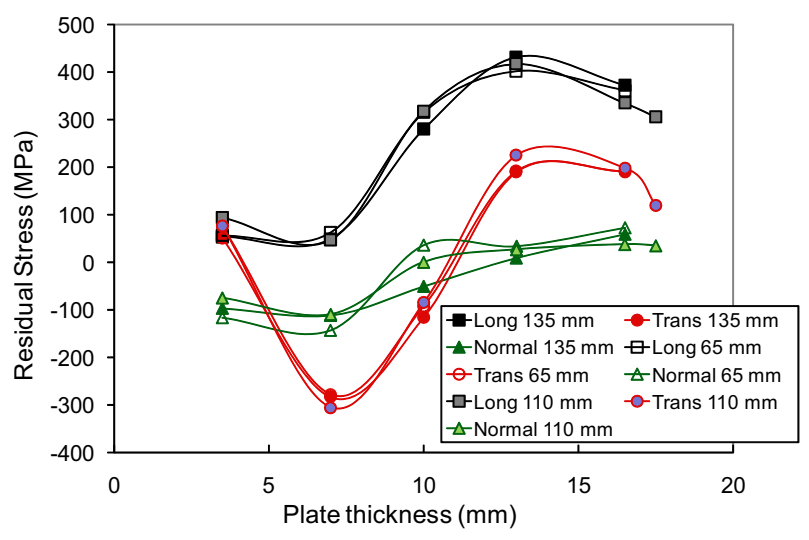

Fig. 6. Comparison of through-thickness residual stress profiles at $x=65,110$ and $135 \mathrm{~mm}$ of the 8-pass groove weld specimen without weld interruptions (Plate 3).

deposited in passes 1, 2 and 3 will also have been cyclically hardened, an overall tendency for the weld metal to introduce a bending stress across the thickness of the plate may be more significant as the mid-thickness of the plate is approached.

Interestingly, it can be observed in Fig. 5 that the tensile hot spot in longitudinal stress at the ramped weld stop-start feature has almost disappeared, while the corresponding hot spot for the abrupt stop-start feature still remains after three subsequent weld passes have been deposited. The trend is similar for the maps of transverse residual stress.

The through-thickness residual stress profiles for Plate 3 are shown in Fig. 6, at distances of 65, 110 and $135 \mathrm{~mm}$ along the weld. For each component of stress, there is very close agreement between the values measured at each position. These results suggest that the plates were large enough for steady-state conditions to be reached at positions between 65 and $135 \mathrm{~mm}$ along the weld. In Plates 1 and 2 the interruptions at 65 and $135 \mathrm{~mm}$ were separated by a distance equal to 6 times the length of the weld pool, and it is hoped that this distance was sufficiently large to minimise any influence that one interruption might have had on the other.

Finally, the variations in stress along the welding direction are plotted for Plates 1 and 2 at the approximate depth of the fifth weld pass $(y=13 \mathrm{~mm})$ in Fig. 7. This plot was constructed so that conclusions could be drawn simply by examining the estimated

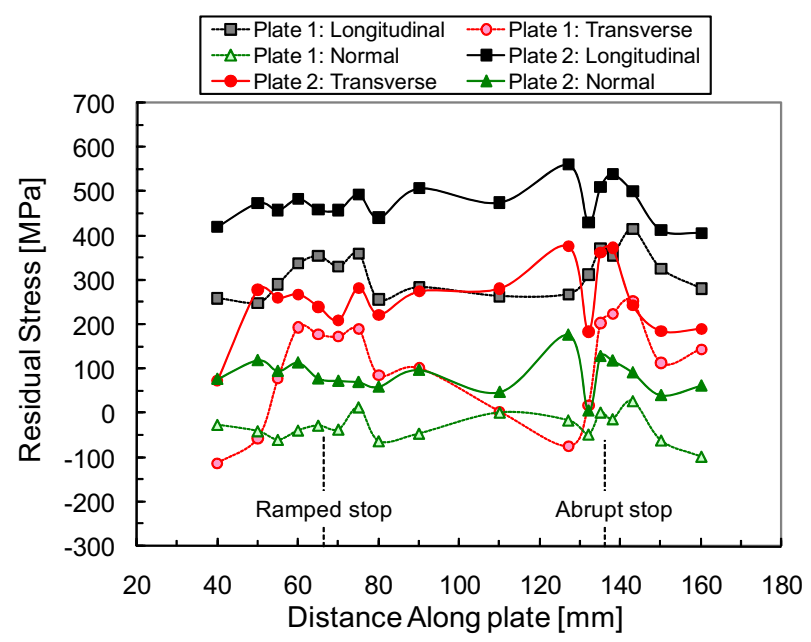

Fig. 7. A comparison of residual stress profiles between Plate 1 ( 5 pass) and Plate 2 ( 8 pass), along profile $y=13 \mathrm{~mm}$ (i.e. $13 \mathrm{~mm}$ from the bottom of the plate). This corresponds approximately to the position of the 5 th weld pass. stresses at individual measurement locations. When interpreting these data, the authors estimated the uncertainties in stress based on the uncertainties in the fitting of the diffraction peaks for each component of strain, and the measurement for $d_{0}$. In general, the combined uncertainty in peak fitting was found to give rise to an uncertainty in stress of approximately $20 \mathrm{MPa}$.

If we assume that the stress levels at a distance of $110 \mathrm{~mm}$ along the plate were approaching steady-state values then, for the longitudinal component of stress in the 5-pass weld, the ramped interruption can be seen to increase the stress by $\sim 100 \mathrm{MPa}$ from the steady-state stress, while the abrupt interruption can be seen to result in an increase of approximately $150 \mathrm{MPa}$. In Plate 2, it is evident that all stresses at positions corresponding to the fifth weld pass are increased in magnitude by approximately $300 \mathrm{MPa}$, owing to the strain hardening that would have occurred during the deposition of three subsequent weld passes. However, the results also reveal a persistent localised increase in residual stress of approximately $70-80 \mathrm{MPa}$ at the abrupt weld interruption, while there is little evidence of any localised increase in residual stress near the ramped weld interruption.

It is interesting to note that Fig. 7 also shows an apparent sharp drop in residual stress immediately before the abrupt weld interruption, at a single point just over $130 \mathrm{~mm}$ along the plate. Indeed this sharp drop, while against the overall trend, is seen in the residual stresses that were measured in all three orientations, and it is most pronounced in the transverse orientation. The localised drop in stress is in the range between 100 and $150 \mathrm{MPa}$, and is therefore significantly larger than the uncertainties associated with the fitting of diffraction peaks. It is possible that such a drop in stress does occur in reality, but it is perhaps more likely that this perturbation is an artefact arising as a consequence of a local change in the value of $d_{0}$ that has somehow not been captured in the $d_{0}$ measurements. This is, however, indicative of the difficulties that can arise when measuring $d_{0}$ in the weld metal, where strong textures can develop [32], and where intergranular strains can have a significant influence on measured lattice spacings [33]. Given that, in this work, considerable attention is being devoted to the results of diffraction measurements in the weld metal, where such difficulties arise, it would seem sensible to carry out further measurements with an alternative measurement technique, as an independent check on the trends that have emerged from the neutron diffraction measurements.

\section{Incremental deep hole drilling}

Deep hole drilling is a method of residual stress measurement that is based on characterising the deformations that occur when the residual stresses within a material are relieved. Details of the conventional deep hole drilling technique have been described elsewhere [34], so the method will be described only briefly here. In this technique, a reference hole is first drilled through the component in which residual stresses are to be measured, at the location of interest. At each point on the drilling axis, accurate measurements of the diameter of this reference hole are made at a number of angles within the plane that is normal to the drilling axis. A column of material surrounding the reference hole is then trepanned so that it is free from the remainder of the component. Once this process is complete, the reference hole is re-measured, and changes in the diameter of the reference hole and the column height are used to calculate the residual stresses that existed along the drilling axis [34].

The conventional deep hole drilling method has been used previously to measure residual stresses in welded components $[35,36]$. It will not be sensitive to variability in the stress-free lattice parameter $\left(d_{0}\right)$ in the weld metal region, since it is based on the 
relaxation of stresses that occurs when material is trepanned from a component. The method is, however, sensitive to any plastic deformation that may occur during the relaxation of stresses, since the method assumes that all of the stress relaxation is elastic. This can be problematic when near-yield or significant hydrostatic stresses exist in the component being measured, such as is often the case in welds. However, a new variant of the method, referred to as incremental deep hole drilling, has recently been developed as a means of minimising the errors associated with the plastic relaxation of stress under these circumstances. The details of the incremental deep hole drilling technique are described in Ref. [19].

The residual stresses in Plate 2 were measured in two locations using the incremental deep hole drilling technique. These measurements were intended to serve as an independent check on the neutron diffraction measurements, in the hope that any conclusions arising from this work could be drawn with increased levels of confidence. The measurement positions were on the weld centreline, at distances of 110 and $135 \mathrm{~mm}$ along the length of the plate. These locations correspond to a near-steady-state welding condition (at $110 \mathrm{~mm}$ ), and the location of the abrupt weld interruption (at $135 \mathrm{~mm}$ ). Plate 2 was chosen to be the ideal candidate for such a "spot check" on the neutron measurements, since it contained eight weld passes that completely filled the weld groove, thus minimising the probability that any irregularities in the weld geometry (associated with a partly filled weld groove) would affect the measurements.

The results of the incremental deep hole drilling measurements on Plate 2 are shown in Fig. 8, for both the transverse and longitudinal orientations. In Fig. 8, the measured data that were obtained at the same distances along the specimen, using neutron diffraction, are also plotted for comparison. It can be seen that the agreement that is achieved between the neutron diffraction measurements and the measurements carried out with the incremental deep hole drilling technique is excellent. This agreement confirms that the overall trends that were observed in the neutron diffraction measurements are likely to be correct. Note that, in both cases, the measured residual stresses are presented as a function of distance from the back surface of the plate.

The incremental deep hole drilling results alone also suggest that localised increases in stress may occur at the abrupt weld interruption, even after three weld passes have been overlayed on the interruption itself. Unfortunately, since the locations at which stresses were estimated with this method were not identical for each distance along the plate, it is not possible to be conclusive based on these measurements in isolation. However, when consideration is also given to the excellent agreement that these results achieve with the neutron diffraction measurements, as well as the fact that the highest residual stresses were measured at the position of the abrupt weld interruption with both residual stress measurement techniques, it would appear that the localised increases in residual stress at the abrupt weld interruption are real, and that they are not an artefact associated with uncertainties in the measurement of $d_{0}$.

\section{Hardness mapping}

While the mechanisms that lead to the localised stress perturbations surrounding the weld interruptions are as yet unclear, they are likely to be associated with localised variations in the strain history. A comparison of the results for the 5-pass and 8-pass welds in Fig. 7 shows how significant the increases in residual stress can be after subsequent weld passes are deposited. The additional thermal cycles impart further plastic strain and the associated work hardening results in increased residual stresses. It would therefore seem reasonable that a feature such as a weld interruption, which
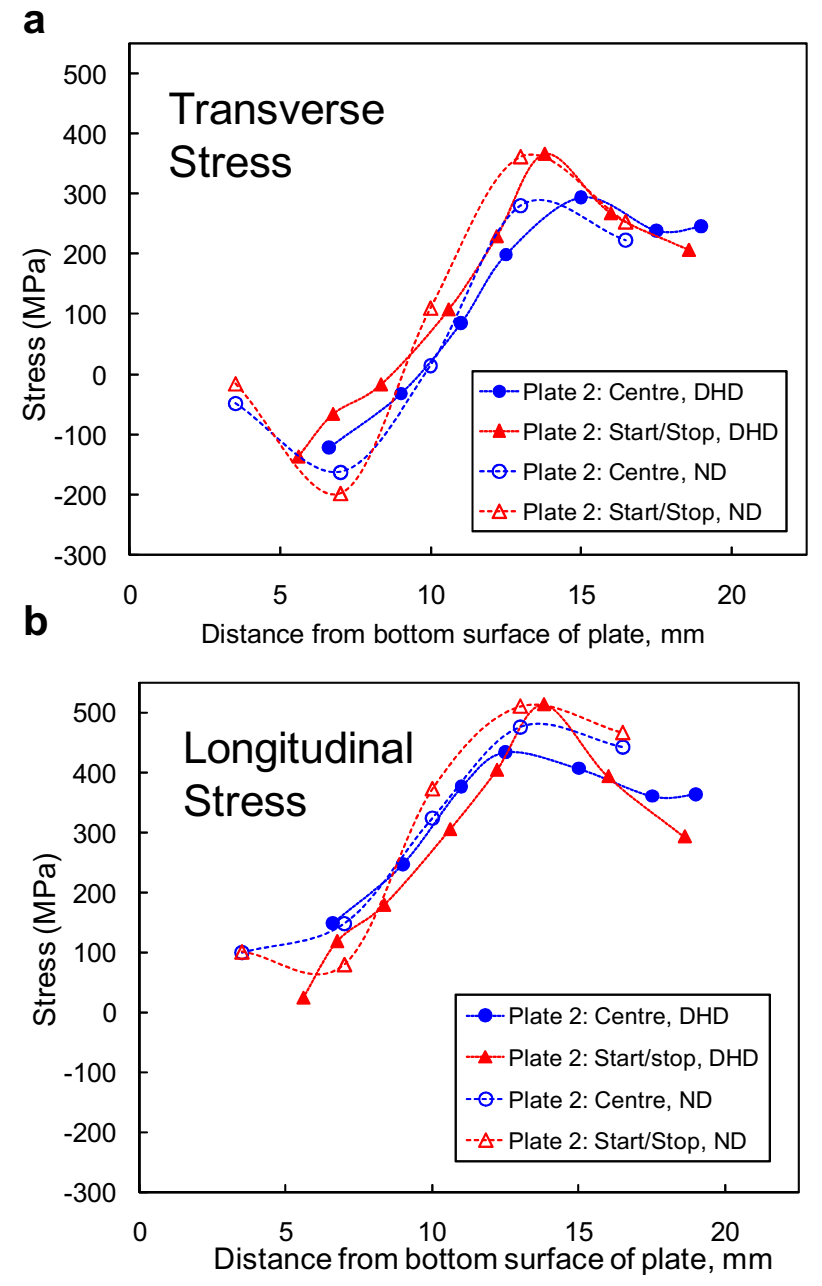

Fig. 8. Through thickness (a) transverse and (b) longitudinal residual stress measurements determined using incremental deep hole drilling and neutron diffraction for plate 2 , at the plate centre and at the abrupt start/stop location.

would introduce localised variations in the strain history, would also produce perturbations in the stress field. It is also unsurprising that such perturbations would be more significant in the case of an abrupt interruption. One might expect, however, that if such a perturbation in the strain history does arise, there would also be a corresponding perturbation in the hardness.

After the residual stress measurements were completed, a $5 \mathrm{~mm}$ thick slice was extracted by EDM cutting from Plate 2 so that hardness testing could be carried out. The extraction of this slice was carefully controlled so that one surface of the slice coincided with the plane of the weld centreline, and this surface was subsequently ground and polished to achieve a $1 \mu \mathrm{m}$ surface finish.

Vickers hardness testing was carried out using a $5 \mathrm{~kg}$ load. In the through-thickness direction, measurements were arranged in rows at nominal $y$-values (or distances from the back surface of the sample) of $2.5,7.5,11.5,12.5,13.5$ and $17.5 \mathrm{~mm}$. The density of measurements was increased between $y=11.5$ and $y=13.5 \mathrm{~mm}$ to coincide with the approximate location of the fifth weld pass, which contained the interruptions. In the direction of welding, the measurement locations were nominally spaced at $5 \mathrm{~mm}$ intervals. Given the levels of scatter that are often associated with hardness testing, three indents were made at each nominal measurement location, and the average of these three values was used as the basis for interpretation. The results of the hardness testing are shown in 


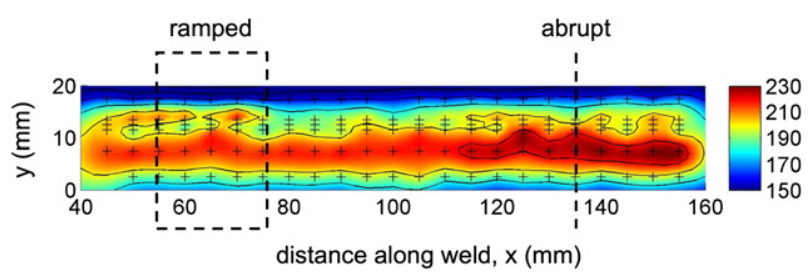

Fig. 9. A contour map for Vickers hardness on the plane of the weld centreline in Plate 2 , as obtained with a $5 \mathrm{~kg}$ load. The welding direction is from left to right, and the locations of the ramped and abrupt interruptions are highlighted. There is a region of elevated hardness in the vicinity of the abrupt interruption (from 115 to $150 \mathrm{~mm}$ ), but not for the ramped interruption. Each cross on the figure denotes a nominal measurement location. Three indents were made local to each nominal measurement location.

the form of a contour map in Fig. 9. The nominal measurement locations are marked by crosses on the map.

The results in Fig. 9 show a region across which the highest hardnesses were measured, and this region traverses the abrupt weld interruption. This region is approximately $7-8 \mathrm{~mm}$ above the bottom surface of the plate and it stretches from approximately 115-150 $\mathrm{mm}$ along the weld. Interestingly, elevated stresses were measured in the same specimen between $125 \mathrm{~mm}$ and $140 \mathrm{~mm}$ along the plate (see Fig. 7). Meanwhile, there do not appear to be any localised change in hardness coinciding with the ramped interruption. Thus, the hardness results are consistent with the localised stresses associated with the ramped interruption being annealed during the deposition of the subsequent three weld passes. In contrast, this annealing effect appears to be less effective at the abrupt interruption, and increased levels of residual stress persist.

\section{Conclusions}

The following conclusions can be drawn from this work:

- Interruptions in AISI grade 304L/308L austenitic stainless steel welds, such as those that occur when it is necessary to grind out a weld defect or change a reel of filler wire, are likely to lead to localised increases in tensile residual stresses.

- In this study, the localised increases in stresses were found to be greater when the interruption was abrupt than when the interruption was ramped, being approximately $150 \mathrm{MPa}$ in the former case and approximately $100 \mathrm{MPa}$ for the latter.

- If subsequent weld passes are overlayed on the stop-start feature, a localised increase in residual stress is likely to persist if the interruption is abrupt, but any such increase may be dissipated in the case of ramped interruptions.

- In situations where weld interruptions can be anticipated, there may be benefits associated with specifying that these interruptions be ramped, rather than abrupt.

\section{Acknowledgements}

This research project was supported by the European Commission under the 6th Framework Programme through the Key Action: Strengthening the European Research Area, Research Infrastructures, Contract No: RII3-CT-2003-505925. The allocation of beam time on the STRESS-SPEC instrument at Forschungsneutronenquelle Heinz Maier-Leibnitz (FRM-II) is gratefully acknowledged. The authors are equally grateful to the Paul Scherrer Institute in Switzerland for the allocation of beam time on the POLDI diffractometer.

The authors are indebted to Drs. J. Rebelo Kornmeier and M. Hofmann for assistance at FRM II, and to Drs. U. Stuhr and G. Schuck for assistance at the Paul Scherrer Institute. Thanks are also due to
Drs. C.T. Watson and C.M. Gill at Rolls-Royce and A. P. Warren at Serco Technical Services for helpful discussions. MT and JAF are grateful for support from Rolls-Royce Marine.

\section{References}

[1] Hornbach DJ, Prevey PS. The effect of prior cold work on tensile residual stress development in nuclear weldments. Journal of Pressure Vessel Technology Transactions of the ASME 2002;124(3):359-65.

[2] Turski M, Bouchard PJ, Steuwer A, Withers PJ. Residual stress driven creep cracking in AISI type 316 stainless steel. Acta Materialia 2008;56(14): 3598-612.

[3] Bouchard PJ, Withers PJ, Mcdonald SA, Heenan RK. Quantification of creep cavitation damage around a crack in a stainless steel pressure vessel. Acta Materialia 2004;52(1):23-34.

[4] Cheng XH, Fisher JW, Prask HJ, Gnaupel-herold T, Yen BT, Roy S. Residual stress modification by post-weld treatment and its beneficial effect on fatigue strength of welded structures. International Journal of Fatigue 2003; 25(9-11):1259-69.

[5] Fricke W. Effects of residual stresses on the fatigue behaviour of welded steel structures. Materialwissenschaft und Werkstofftechnik 2005;36(11):642-9.

[6] Lidbury DPG. The significance of residual stresses in relation to the integrity of LWR pressure vessels. International Journal of Pressure Vessels and Piping 1984;17(4):197-328.

[7] Read DT. Measurement of applied J-Integral produced by residual-stress. Engineering Fracture Mechanics 1989;32(1):147-53.

[8] Ainsworth RA, Sharples JK, Smith SD. Effects of residual stresses on fracture behaviour - experimental results and assessment methods. Journal of Strain Analysis for Engineering Design 2000;35(4):307-16.

[9] Ainsworth RA. R5 procedures for assessing structural integrity of components under creep and creep-fatigue conditions. International Materials Reviews 2006;51(2):107-26.

[10] Lei Y, O'dowd NP, Webster GA. Fracture mechanics analysis of a crack in a residual stress field. International Journal of Fracture 2000;106(3):195-216.

[11] Bouchard PJ, Withers PJ. The appropriateness of residual stress length scales in structural integrity. Journal of Neutron Research 2004;12(1):81-91.

[12] Withers PJ, Bhadeshia HKDH. Residual stress part 1 - measurement techniques. Materials Science and Technology 2001;17(4):355-65.

[13] Withers PJ, Bhadeshia HKDH. Residual stress part 2 - nature and origins. Materials Science and Technology 2001;17(4):366-75.

[14] Francis JA, Bhadeshia HKDH, Withers PJ. Welding residual stresses in Ferritic power plant Steels. Materials Science and Technology 2007;23(9): 1009-20.

[15] Masubuchi K. Analysis of welded structures - residual stresses, distortion, and their consequences. Permagon Press Ltd; 1980. p. 189-234.

[16] Bouchard PJ, Santisteban JR, Edwards L, Turski M, James J, Pratihar S. et al. Residual stress measurements revealing weld bead start and stop effects in single and multi-pass weld-runs. In: Proceedings of the ASME Pressure Vessels and Piping Conference, vol. 6, 2005. p. 853-60

[17] Pratihar S, Turski M, Edwards L, Bouchard PJ. Neutron diffraction residual stress measurements in a 316L stainless steel bead-on-plate weld specimen. International Journal of Pressure Vessels and Piping 2009;86(1):13-9.

[18] Turski M, Edwards L. Residual stress measurement of a 3161 stainless steel bead-on-plate specimen utilising the contour method. International Journal of Pressure Vessels and Piping 2009;86(1):126-31.

[19] Mahmoudi AH, Hossain S, Truman CE, Smith DJ, Pavier MJ. A new procedure to measure near yield residual stresses using the deep hole drilling technique. Experimental Mechanics 2009;49:595-604

[20] Turski M, Francis JA, Withers PJ. Determination of residual stress at weld interruptions by neutron diffraction. Zeitschrift Für Kristallographie 2008; Supplement 27:231-43.

[21] Hutchings MT, Withers PJ, Holden TM, Lorentzen T. Introduction to the characterisation of residual stress by neutron diffraction. Boca Raton, Florida: Taylor \& Francis; 2005. p. 203-63.

[22] Clausen B, Lorentzen T, Leffers T. Acta Materialia 1998;46:3087-98.

[23] Fitzpatrick ME, Lodini A. Analysis or residual stress by diffraction using neutron and synchrotron diffraction. Taylor \& Francis; 2003. p. 120.

[24] Kröner E. Zeitschrift Für Physik 1958;5:504-18.

[25] Apfel A, Moysan J, Courneloup G, Fouquet T, Chassignole B. Coupling an ultrasonic propagation code with a model of the heterogeneity of multipass welds to simulate ultrasonic testing. Ultrasonics 2005;43:447-56.

[26] Sharma S. Investigation of elastic anisotropy and texture of austenitic stainless steel weld metal using diffraction and self-consistent modelling. PhD thesis, The Open University; 2009.

[27] Suzuki H, Holden TM. Neutron diffraction measurements of stress in an austenitic butt weld. Journal of Strain Analysis for Engineering Design 2006; 41(8):575-82.

[28] Krawitz AD, Winholtz R. Use of position-dependent stress-free standards for diffraction stress measurements. Materials Science and Engineering A 1994; 185(1-2):123-30.

[29] Matlab: version 7.2 (R2006a). Natick, MA: The Math Works, Inc.; 2006.

[30] Sandwell DT. Biharmonic spline interpolation of Geos-3 and seasat altimeter data. Geophysical Research Letters 1987;14:139-42. 
[31] Turski M, Smith MC, Bouchard PJ, Edwards L, Withers PJ. Spatially resolved materials property data from a uniaxial cross-weld tensile test. Journal of Pressure Vessel Technology - Transactions of the ASME 2009; 131:061406.

[32] Huang YM, Wu YM, Pan CX. EBSD study of solidification characteristics of austenitic stainless steel weld pool. Materials Science and Technology 2010 26(6):750-3.

[33] Holden TM, Suzuki H, Carr DG, Ripley MI, Clausen B. Stress measurements in welds: problem areas. Materials Science and Engineering A 2006;437(1): 33-7.
[34] Smith DJ, Bouchard PJ, George D. Measurement and prediction of residual stresses in thick-section steel welds. Journal of Strain Analysis for Engineering Design 2000;35(4):287-305.

[35] Hilson G, Simandjuntak S, Flewitt PEJ, Hallam KR, Pavier MJ, Smith DJ. Spatial variation of residual stresses in a welded pipe for High temperature applications. International Journal of Pressure Vessels and Piping 2009;86(11):748-56.

[36] Bouchard PJ, George D, Santisteban JR, Bruno G, Dutta A, Edwards L, et al. Measurement of the residual stresses in a stainless steel pipe girth weld containing long and short repairs. International Journal of Pressure Vessels and Piping 2005;82(4):299-310. 